\title{
Unusual a cause of quadriparesis: Hypokalemia; A case report
}

\author{
Seyit Kağan Başarslan ${ }^{a^{*}}$, Ali Karakuşs ${ }^{\mathrm{b}}$, Murat Çevik ${ }^{\mathrm{c}}$ \\ ${ }^{a}$ Mustafa Kemal University, Faculty of Medicine, Neurosurgery Department, Hatay, Turkey \\ ${ }^{b}$ Mustafa Kemal University, Faculty of Medicine, Emergency Department, Hatay, Turkey \\ ${ }^{c}$ Mustafa Kemal University, Faculty of Medicine, Internal Medicine Department, Hatay, Turkey
}

$\begin{array}{ll}\text { ARTICLE INFO ABSTRACT } & \text { ABST }\end{array}$

\section{Article History \\ Received $\quad 06 / 10 / 2013$ \\ Accepted $\quad 29 / 10 / 2013$}

\section{* Correspondence to:}

Seyit Kağan Başarslan

Mustafa Kemal University,

Faculty of Medicine,

Neurosurgery Department,

Hatay, Turkey

e-mail: kaganbasarslan@hotmail.com

\begin{abstract}
We report a 45-year-old male who presented with acute quadriparesis with severe hypokalemia. He recovered completely on potassium supplementation. Not only being contentedwith radiological examinations,clinicians should also be aware of biochemical parameters and consider hypokalemia in the differential diagnosis while evaluating acute quadriparesis.
\end{abstract}

J. Exp. Clin. Med., 2013; 30:403-404

\section{Keywords:}

Atypical

Hypokalemia

Quadriparesis

Rare presentation

\section{Introduction}

Neural tissue comprises different functional units those can not tolerate compression on it.In case of thein volvement orpressure on, it can not ableto function. This may also reflect as motor weakness in then eurologicalstatus. Anycase who have loss of motor function, is needed to determine the etiological factorurgently. We present a case whom etiopatogenesis remained unclearby radiologicalin vestigation, and to draw attention into the rare cause of quadriparesis.

\section{Case}

A 45-year-old male was brought to the emergency room complaining of sudden loss of strength over four extremities. On neurological examinations, he had flaccid paraplegia and $3 / 5$ weakness at the upper extremities. On the history, there had been no such as complaint before and his medical background was normal. He had only taken an antibiotic and analgezic due to throat infection for a week and a history of trauma was not expressed. In order to explain the etiology of acutely developped quadriparesis, starting with cervical and cranial then, whole spine MR imaging was performed, but revealed no pathology. Arrival blood biochemistry was all normal ranges except the potassium value that was as low as only $2.1 \mathrm{mEq} / \mathrm{L}$. The biochemical analysis was asked to be repeated. Neurological consultation reported that it could be Guillain-Barré syndrome and internal Medicine suggested the potassium replacement therapy, and it was promptly began. The same day other potassium values were $2.3,2.6 \mathrm{mEq} / \mathrm{L}$ respectively, and patient was kept on taking the potassium replacement therapy. On the second day, the control potassium values of the patient were found as 2.9 and 3.3 $\mathrm{mEq} / \mathrm{L}$ respectively, and his paresis was started to decrease gradually. Hence, the etiology of acutely reduced potassium was investigated and it was interpreted to be up to the drugs interaction used for upper respiratory tract infections. On the third day, he was mobilized, and then discharged on next day without neurological deficit. 


\section{Discussion}

The interesting feature of this case was the presentation with severe isolated hypokalemia, causing acute flaccid quadriparesis that is extremely rare (Singer and Brenner, 2008). Sudden life-threatening hypokalemia with muscle paralysis is one the most serious and confusing clinical manifestation by majority of neurosurgeons (Poux et al., 1992). In case of sudden loss of motor function, etiological agent is always sought throughout nervous system and biochemical parameters are generally ignored (Gulati and Maheshwari, 2007). In the patient, the pure motor quariparesis was due to hypokalemia and he had dramatic recovery with the supplementation of potassium. We investigated the other causes of hypokalemic paralysis such as thyrotoxicosis, alcohol, drugs, gastrointestinal loss and urinary potassium wasting syndrome by clinical examination and relevant investigations, but all challenge was negative. The report warrants further documentation and studies of acute pure motor weakness in case its etiology remained unclear.

Clinicians should be aware of such an association especially in biochemical parameters and consider hypokalemia in the differential diagnosis while evaluating acute quadriparesis.

Acutely developed hypokalemia sometimes present itself with paresis. While investigating the etiology of severe symptoms like quatriparesis, the value of blood potassium should also be taken into consideration.

\section{REFERENCES}

Singer, G.G., Brenner, B.M., 2008. Fluid and electrolyte disturbances. In: Fauci, A.S., Braunwald, E., Kasper, D.L., Hauser, S.L., Longo, D.L., Jameson, J.L., Loscalzo, J., editors. Harrison's principles of internal medicine. 17 ${ }^{\text {th }}$ ed. New York: Mcgraw-Hill Companies. p. $274-285$.

Poux, J.M., Peyronnet, P., Meur, R.L., Favereau, J.P., Charmes, J.P., Robert, C.L., 1992. Hypokalemic quadriplegia and respiratory arrest revealing primary Sjögren's syndrome. Clin Nephrol. 37, 189-191.

Gulati, S., Maheshwari, A., 2007. Atypical manifestations of dengue. Trop. Med. Int. Health. 12, 1087-1095. 